\title{
Joint association of urinary sodium and potassium excretion with cardiovascular events and mortality: prospective cohort study
}

\author{
Martin O'Donnell, ${ }^{1,2}$ Andrew Mente, ${ }^{1}$ Sumathy Rangarajan, ${ }^{1}$ Matthew J McQueen, ${ }^{1}$ Neil O'Leary, \\ Lu Yin, ${ }^{3}$ Xiaoyun Liu, ${ }^{3}$ Sumathi Swaminathan, ${ }^{4}$ Rasha Khatib, ${ }^{5}$ Annika Rosengren, ${ }^{6}$ \\ John Ferguson, ${ }^{2}$ Andrew Smyth, ${ }^{2}$ Patricio Lopez-Jaramillo,, Rafael Diaz, ${ }^{8}$ Alvaro Avezum, ${ }^{9}$ \\ Fernando Lanas, ${ }^{10}$ Noorhassim Ismail, ${ }^{11}$ Khalid Yusoff, ${ }^{12}$ Antonio Dans, ${ }^{13}$ Romaina Iqbal, ${ }^{14}$ \\ Andrzej Szuba, ${ }^{15}$ Noushin Mohammadifard, ${ }^{16}$ Atyekin Oguz, ${ }^{17}$ Afzal Hussein Yusufali, ${ }^{18}$ \\ Khalid F Alhabib, ${ }^{19}$ Iolanthe M Kruger, ${ }^{20}$ Rita Yusuf, ${ }^{21}$ Jephat Chifamba, ${ }^{22}$ Karen Yeates, ${ }^{23}$ \\ Gilles Dagenais, ${ }^{24}$ Andreas Wielgosz, ${ }^{25}$ Scott A Lear, ${ }^{26}$ Koon Teo, ${ }^{1}$ Salim Yusuf, ${ }^{1}$ \\ the PURE Investigators
}

Accepted: 5 February 2019

\begin{abstract}
For numbered affiliations see end of the article Correspondence to: M O’Donnell odonnm@mcmaster.ca (ORCID 0000-0002-7347-776) Additional material is published online only. To view please visit the journal online.

Cite this as: BMJ 2019;364:1772 http://dx.doi.org/10.1136/bmj.l772
\end{abstract}

\begin{abstract}
OBJECTIVE

To evaluate the joint association of sodium and potassium urinary excretion (as surrogate measures of intake) with cardiovascular events and mortality, in the context of current World Health Organization recommendations for daily intake ( 22.0 g sodium, $>3.5$ g potassium) in adults.

DESIGN

International prospective cohort study.
\end{abstract}

SETTING

18 high, middle, and low income countries, sampled from urban and rural communities.

PARTICIPANTS

103570 people who provided morning fasting urine samples.

\section{MAIN OUTCOME MEASURES}

Association of estimated 24 hour urinary sodium and potassium excretion (surrogates for intake) with all cause mortality and major cardiovascular events, using multivariable Cox regression. A six category variable for joint sodium and potassium

\section{WHAT IS ALREADY KNOWN ON THIS TOPIC}

Dietary guidelines recommend sodium restriction but increased potassium intake (WHO recommends $<2.0 \mathrm{~g} /$ day and $>3.5 \mathrm{~g} /$ day, respectively)

Studies evaluation the association of sodium intake have reported inconsistent findings, but many report a J-shaped association, while those evaluating potassium intake generally report a linear reduction in mortality with increasing potassium intake

Most observational studies have reported on the effects of sodium and potassium intake separately, although some have reported on the association of sodium:potassium ratio with clinical outcomes

\section{WHAT THIS STUDY ADDS}

The study findings question the feasibility of the WHO simultaneous target of low sodium intake ( $(2 \mathrm{~g} /$ day) with high potassium intake $(>3.5 \mathrm{~g} /$ day), which was consumed by a very low proportion of the population.

The combination of moderate sodium intake (3-5 g/day) with higher potassium intake was associated with the lowest risk of mortality and cardiovascular events The J-shaped association of sodium intake with mortality and cardiovascular events does not lend support to the current WHO recommendation to consume low sodium diets ( $(2.0 \mathrm{~g} /$ day), and it also argues against use of the sodium:potassium ratio was generated: sodium excretion (low ( $<3 \mathrm{~g} /$ day), moderate (3-5 g/day), and high ( $>5 \mathrm{~g} /$ day) sodium intakes) by potassium excretion (greater/equal or less than median $2.1 \mathrm{~g} /$ day).

\section{RESULTS}

Mean estimated sodium and potassium urinary excretion were $4.93 \mathrm{~g} / \mathrm{day}$ and $2.12 \mathrm{~g} / \mathrm{day}$, respectively. After a median follow-up of 8.2 years, 7884 (6.1\%) participants had died or experienced a major cardiovascular event. Increasing urinary sodium excretion was positively associated with increasing potassium excretion (unadjusted $r=0.34$ ), and only $0.002 \%$ had a concomitant urinary excretion of $<2.0 \mathrm{~g} /$ day of sodium and $>3.5 \mathrm{~g} /$ day of potassium. A J-shaped association was observed of sodium excretion and inverse association of potassium excretion with death and cardiovascular events. For joint sodium and potassium excretion categories, the lowest risk of death and cardiovascular events occurred in the group with moderate sodium excretion (3-5 g/day) and higher potassium excretion (21.9\% of cohort). Compared with this reference group, the combinations of low potassium with low sodium excretion (hazard ratio $1.23,1.11$ to $1.37 ; 7.4 \%$ of cohort) and low potassium with high sodium excretion $(1.21,1.11$ to $1.32 ; 13.8 \%$ of cohort) were associated with the highest risk, followed by low sodium excretion $(1.19,1.02$ to $1.38 ; 3.3 \%$ of cohort) and high sodium excretion (1.10, 1.02 to $1.18 ; 29.6 \%$ of cohort) among those with potassium excretion greater than the median. Higher potassium excretion attenuated the increased cardiovascular risk associated with high sodium excretion ( $P$ for interaction $=0.007$ ).

\section{CONCLUSIONS}

These findings suggest that the simultaneous target of low sodium intake ( $(2 \mathrm{~g} /$ day) with high potassium intake ( $>3.5 \mathrm{~g} /$ day) is extremely uncommon. Combined moderate sodium intake (3-5 g/day) with high potassium intake is associated with the lowest risk of mortality and cardiovascular events.

\section{Introduction}

Consumption of sodium and potassium is essential to health, as neither are produced endogenously and both are necessary for critical physiological processes. ${ }^{1-3}$ Maintaining homeostasis requires a 
mutual interdependence of sodium and potassium, meaning that their relation with health is necessarily linked. ${ }^{1-3}$ Despite these fundamental physiological considerations, current public health policy adopts markedly opposing guidance for sodium and potassium intake, with the World Health Organization recommending an extremely low sodium intake $(<2 \mathrm{~g} /$ day, whereas the current average intake is about $4 \mathrm{~g} /$ day) but high potassium intake ( $>3.5 \mathrm{~g} /$ day, whereas the average intake is about $2 \mathrm{~g} /$ day) in the entire adult population..$^{4-6}$ International data on the percentage of people with very low intakes of sodium and simultaneously high potassium intakes ${ }^{7}$ and the joint effects on health outcomes from large international epidemiological studies are limited. ${ }^{45} 89$

Current public health policy on targets for sodium intake is based primarily on small, and mostly short term, clinical trials evaluating the relation of changes in sodium and potassium intake with blood pressure. $^{4} 8$ Although clinical trials have reported a decrease in blood pressure with a reduction in sodium intake, ${ }^{8}$ many prospective cohort studies have reported a J-shaped association of sodium intake and cardiovascular disease or mortality, ${ }^{10-16}$ with an increased risk emerging at sodium intakes $<2.7 \mathrm{~g} /$ day and $>5$ g/day. ${ }^{10}$ The increased cardiovascular risk associated with high sodium intake seems to be especially in those with hypertension, ${ }^{17}$ whereas the increased risk associated with low sodium intake might be mediated through activation of physiological systems to conserve sodium (eg, reninangiotensin-aldosterone system). ${ }^{18}$ In contrast, the association of potassium intake with blood pressure and cardiovascular disease is consistent, with a linear reduction in blood pressure and cardiovascular risk with increasing potassium intake reported in most studies. ${ }^{9}$ Some epidemiological studies report an interactive association of sodium and potassium intake with blood pressure, and other studies report use of sodium:potassium ratios for predicting risk of cardiovascular events and mortality. ${ }^{19-25}$ Whether a potential modifying effect of increased potassium intake is directly causal or simply a marker of improved diet quality, ${ }^{26}$ as diets rich in fruit and vegetables (which are associated with lower cardiovascular risk) are high in potassium, is uncertain.

In the Prospective Urban Rural Epidemiological (PURE) Study, we have previously reported on the intermediate term (3.7 years of follow-up $)^{1617}$ association of sodium and potassium intake with mortality and cardiovascular events. In the current analyses, we further explore the association of sodium and potassium intake with death and cardiovascular disease in extended follow-up (eight years).

\section{Methods}

\section{Study population}

The PURE Study is a large scale epidemiological cohort study that has enrolled people (aged 35 to 70 years) residing in 628 urban and rural communities in low, middle, and high income countries (Bangladesh,
India, Pakistan, Zimbabwe, Argentina, Brazil, Chile, Malaysia, Poland, South Africa, Turkey, China, Colombia, Iran, Canada, Sweden, Palestinian territories occupied by Israel, and United Arab Emirates). ${ }^{27-29}$ The supplementary appendix describes the selection of participants. Recruitment began in January 2003. Participants provided written informed consent. For the current analysis, we included 103570 participants from 18 countries who collected early morning fasting urine samples suitable for analysis, of which 103200 (99.6\%) had follow-up information available (95\% completed at least one follow-up visit). The Population Health Research Institute of Hamilton Health Sciences, Ontario, Canada coordinated the study.

\section{Exposure assessments}

A morning fasting midstream urine sample, collected from each participant, was frozen at $-20^{\circ} \mathrm{C}$ to $-70^{\circ} \mathrm{C}$ and shipped to a central laboratory in Canada, China, India, or Turkey. The samples were shipped at ambient temperature using the STP 250 ambient specimen shipping box (see supplementary appendix for a description of the methods used for performing urinary analyses). We used the Kawasaki formula to estimate 24 hour urinary sodium and potassium excretion from a fasting morning sample, and these estimates have been validated previously versus measured with 24 hour urine collection. ${ }^{3031}$ An international validation study reported an intraclass correlation of Kawasaki formula to actual 24 hour urine collections of $0.71 .^{31}$ Therefore, we used the estimates derived from fasting morning urine as surrogates for sodium and potassium intake in the study. (The supplementary appendix provides summary details of validation of this approach.)

\section{Ascertainment of outcomes}

Standardised case report forms were used to capture major cardiovascular events (myocardial infarction, stroke, and heart failure), cancer, and death at followup, which were adjudicated using standardised definitions. ${ }^{32}$ For the current analysis, we included all adjudicated outcome events in the PURE database up to September 2017. The primary composite outcome was all cause mortality or myocardial infarction or stroke or heart failure. Secondary outcomes were individual components of the primary composite outcome, and new diagnosis of cancer on follow-up.

\section{Ascertainment of covariates}

All participants completed baseline standardised questionnaires, which included detailed information on age, sex, lifestyle risk factors (eg, smoking, diet, physical activity, alcohol intake), comorbidities (eg, history of diabetes, hypertension, cardiovascular disease), physical measurements (blood pressure, heart rate, body mass index (BMI), waist:hip ratio), and laboratory measurement of lipoproteins (88\%). A modified alternative healthy eating index (mAHEI) score was used to measure overall diet quality, with higher scores indicating a healthier diet. ${ }^{33}$ 


\section{Statistical analyses}

Baseline differences in characteristics between study participants in different categories of estimated sodium and potassium excretion have been reported previously (see supplementary appendix). ${ }^{25}$ Restricted cubic spline plots were used to explore the shape of association between estimated sodium and potassium excretion and outcomes, fitting a restricted cubic spline function with four knots (5th, 35th, 65th, and 95th centiles). ${ }^{34}$ Our primary outcome measure was the composite of all cause mortality and major cardiovascular events (cardiovascular death, stroke, myocardial infarction, and heart failure). Secondary outcomes included individual components of the primary outcome.

Based on our restricted cubic spline plots for the primary outcome, and the results of previous analyses, ${ }^{13}{ }^{16}$ we selected 4.00 to $4.99 \mathrm{~g} /$ day as the reference category for sodium excretion and $<1.5 \mathrm{~g} /$ day for potassium excretion. We modelled the time to event outcome using multivariable Cox regression proportional hazards analysis with mixed effect (centre included as a random effect variable to account for clustering by research site) to determine the association between estimated urinary sodium and potassium excretion and outcomes, using three sequential models. Model 1 (primary model) adjusted for age (included as spline function), sex, education, current and former alcohol intake (units weekly), diabetes mellitus, BMI, physical activity, history of cardiovascular events, use of cardiovascular drugs (blood pressure lowering, statins, or antidiabetics), history of tuberculosis, cancer, HIV, and current and former smoking, which constituted our primary multivariable model (with an additional model that included low density lipoprotein (LDL) cholesterol:high density lipoprotein (HDL) cholesterol ratio). Model 2 also included caloric intake, estimated potassium (or sodium) excretion, waist:hip ratio, and modified mAHEI. Model 3 also included history of hypertension, and baseline systolic and diastolic blood pressure and heart rate, which are in the putative causal pathway. We performed an analysis of the combined effects of sodium and potassium, in which we generated six categories for sodium excretion (low ( $<3 \mathrm{~g} /$ day), moderate (3-5 g/day), and high ( $>5 \mathrm{~g} /$ day)), and potassium excretion above and below the median ( $2.1 \mathrm{~g} /$ day). Three categories were selected for sodium excretion, as the estimated association was J-shaped, whereas two categories were selected for potassium excretion, as the association was linear in analyses. We also completed a stratified subgroup analysis of the association between sodium excretion and outcomes, stratified by groups of urinary potassium excretion and mAHEI divided at the tertiles. We tested for interactions between sodium excretion and potassium excretion and between sodium excretion and mAHEI score. As the association of sodium excretion and composite outcome was non-linear, we tested for interaction above and below median sodium excretion (ie, four tests for interaction), modelling the log hazard ratio as a piecewise linear function of sodium excretion; two connected lines above and below the median sodium excretion with different slopes could interact with the potassium and mAHEI subgroups. We completed an analysis of "usual" sodium intake, based on repeated measurement in 494 participants, employing methodology used in previous publications. ${ }^{25}$

To minimise the potential for reverse causation, we conducted sensitivity analyses that excluded participants with a final follow-up or outcome event within the first three years of baseline. To assess the changes in hazard for the primary outcome with simultaneous changes in sodium and potassium excretion, the hazard ratio was modelled using a two dimensional natural cubic spline. For each of sodium and potassium, two knot points were selected at the tertiles of the variable's sample distribution. This resulted in a grid of four knot points on a two dimensional (sodium and potassium) spline surface. The Cox proportional hazard model then included (along with other covariates) natural cubic spline variables for both sodium and potassium separately and for interaction terms between these spline variables. To visualise the two dimensional change in hazard, and the putative interaction effect between sodium and potassium, estimated hazard ratios were plotted for each observed pair sodium and potassium values in the analysis dataset (a heat map). The reference for plotted hazard ratios was the hazard at the median levels of sodium $(4.70 \mathrm{~g})$ and potassium $(2.1 \mathrm{~g})$.

All analyses were conducted using R Version 3.4.4 (R Foundation for Statistical Computing, Vienna, Austria).

\section{Patient and public involvement}

No patients were involved in setting the research question or outcome measures, or in the design and implementation of the study.

\section{Results}

In total, 103570 participants were included, of whom $41.8 \%$ were from China. In the overall population, mean estimated 24 hour sodium excretion was 4.9 $\mathrm{g}$ and mean estimated potassium excretion $2.1 \mathrm{~g}$. (see supplementary table 1) After a median duration of 8.2 years (interquartile range 6.0-9.4) there were 4524 deaths, 4889 with a major cardiovascular event (1893 myocardial infarctions, 2526 strokes, 534 heart failure, and 1293 cardiovascular deaths), and 7884 had either a cardiovascular event or died, and 3263 had a diagnosis of cancer.

\section{Mortality and cardiovascular events Estimated sodium excretion}

Compared with estimated sodium excretion of 4.00 to $4.99 \mathrm{~g} /$ day (the reference group), higher estimated sodium excretion ( $>7 \mathrm{~g} /$ day) was associated with a greater risk of the primary composite outcome (hazard ratio 1.23, 95\% confidence interval 1.12 to 1.34$)$, all cause mortality $(1.36,1.20$ to 1.53$)$, 
major cardiovascular events (1.20, 1.08 to 1.34$)$, cardiovascular death (odds ratio $1.49,95 \%$ confidence interval 1.21 to 1.84 ), and fatal stroke (hazard ratio 1.76, 95\% confidence interval 1.28 to 2.41) on multivariable analysis (table 1 , supplementary table 2, fig 1).

Compared with estimated sodium excretion of 4.00 to $4.99 \mathrm{~g} /$ day, lower estimated sodium excretion ( $<3 \mathrm{~g} /$ day) was associated with a greater risk of the primary composite outcome (hazard ratio 1.19, 95\% confidence interval 1.09 to 1.30$)$, all cause mortality $(1.26,1.12$ to 1.41$)$, major cardiovascular events $(1.19,1.06$ to $1.33)$, cardiovascular death $(1.35,1.09$ to 1.69$)$, and stroke (1.24, 1.05 to 1.46$)$; supplementary table 2 . No association was found between sodium excretion and cancer or cancer mortality (see supplementary table 2).

\section{Estimated potassium excretion}

Compared with estimated potassium excretion of $<1.5 \mathrm{~g} /$ day, higher estimated potassium excretion was associated with a lower risk of mortality and cardiovascular events $(0.83,0.73$ to 0.94 for $>3 \mathrm{~g} /$ day) on multivariable analysis (fig 2, supplementary table 3). This associated reduction in hazard was greater for mortality risk $(0.71,0.60$ to 0.85$)$ than for major cardiovascular events $(0.87,0.75$ to 1.02$)$. No apparent association was found between potassium excretion and cancer or cancer mortality (see supplementary table 3).

\section{Combined sodium and potassium excretion}

Table 2 shows the association of sodium excretion with the primary composite outcome, categorised by joint sodium and potassium excretion (six categories). The lowest risk of death and cardiovascular events occurred in the group with moderate sodium excretion (3-5 g/day) and higher potassium excretion (21.9\% of cohort). Compared with this reference group, the combinations of low potassium with low sodium excretion (hazard ratio 1.23, 95\% confidence interval 1.11 to $1.37 ; 7.4 \%$ of cohort) and low potassium with high sodium excretion $(1.21,1.11$ to $1.32 ; 13.8 \%$ of cohort) were associated with the highest risk, followed by high sodium excretion (1.10, 1.02 to 1.18 (29.6\% of cohort)) and low sodium excretion (1.19, 1.02 to 1.38; $3.3 \%$ of cohort)) among those with potassium excretion above the median. Moderate sodium excretion with low potassium excretion was associated with an increased risk of the primary outcome (1.10, 1.01 to $1.19 ; 24.0 \%$ of cohort), compared with reference. Few participants $(0.002 \%)$ had both very low sodium excretion $(<2 \mathrm{~g} /$ day) and high potassium excretion ( $>3.5 \mathrm{~g} /$ day $)-\mathrm{a}$ target recommended by nutrition guidelines-so that the risk in this subgroup could not be estimated reliably $(0.2 \%$ for potassium $>2.63 \mathrm{~g} / \mathrm{day}$, assuming that about $75 \%$ of potassium is excreted in the urine, ${ }^{35}$ and sodium excretion $<2.3 \mathrm{~g} /$ day). Figure 3 reports results of a heat map that combines multivariable cubic splines of the association of both sodium excretion and potassium excretion with the primary outcome, with median excretion as reference category. Table 3 and figure 4 show a stratified analysis by thirds of potassium excretion, supporting a lower relative risk associated with higher sodium excretion among those with higher potassium excretion. Test for interaction of higher sodium excretion (above the median) and potassium excretion was significant $(\mathrm{P}=0.007)$ but for lower sodium excretion and potassium excretion was not significant $(\mathrm{P}=0.94)$.

\section{Sodium excretion and diet quality (mAHEI)}

Figure 5 and table 3 report a stratified analysis by mAHEI thirds, which suggest a lower magnitude of risk for the association of sodium excretion with mortality and cardiovascular events among those with higher diet quality scores, although $\mathrm{P}$ for interactions were not significant $(\mathrm{P}=0.87$ for below median excretion and $\mathrm{P}=0.30$ above median excretion).

\begin{tabular}{|c|c|c|c|c|c|c|}
\hline \multirow[b]{2}{*}{ Variables } & \multicolumn{6}{|c|}{ Estimated sodium excretion (g/day) } \\
\hline & $<3(n=11002)$ & $3-3.99(n=21417)$ & $4-4.99(n=26012)$ & $5-5.99(n=21093)$ & $6-6.99(n=12458)$ & $\geq 7(n=11218)$ \\
\hline No of deaths and cardiovascular events & 949 & 1562 & 1816 & 1640 & 964 & 953 \\
\hline Univariate* & $1.23(1.14$ to 1.34$)$ & 1.05 (0.98 to 1.12$)$ & 1.00 & $1.09(1.02$ to 1.17$)$ & $1.07(0.99$ to 1.16$)$ & $1.16(1.07$ to 1.26$)$ \\
\hline Multivariable (primary)† & 1.19 (1.09 to 1.30$)$ & $1.06(0.99$ to 1.14$)$ & 1.00 & $1.08(1.00$ to 1.16$)$ & $1.07(0.98$ to 1.16$)$ & $1.23(1.12$ to 1.34$)$ \\
\hline Multivariable (+diet) & $1.16(1.05$ to 1.27$)$ & $1.06(0.98$ to 1.14$)$ & 1.00 & 1.09 (1.01 to 1.17$)$ & $1.08(0.99$ to 1.18$)$ & $1.26(1.15$ to 1.39$)$ \\
\hline $\begin{array}{l}\text { Multivariable (+blood pressure/heart } \\
\text { rate) }\end{array}$ & $1.15(1.04$ to 1.28$)$ & $1.06(0.98$ to 1.14$)$ & 1.00 & 1.08 (1.00 to 1.16$)$ & $1.06(0.96$ to 1.16$)$ & $1.17(1.06$ to 1.28$)$ \\
\hline $\begin{array}{l}\text { Multivariable } \neq \text { (excluding CVD, diabetes, } \\
\text { smoker, and cancer)§ }\end{array}$ & $1.16(1.03$ to 1.31$)$ & $1.04(0.94$ to 1.15$)$ & 1.00 & 1.08 (0.98 to 1.19$)$ & $1.06(0.95$ to 1.18$)$ & $1.12(0.99$ to 1.25$)$ \\
\hline $\begin{array}{l}\text { Multivariable } \neq \text { (excluding events in first } \\
3 \text { years) }\end{array}$ & $1.20(1.07$ to 1.33$)$ & $1.11(1.02$ to 1.21$)$ & 1.00 & $1.12(1.03$ to 1.21$)$ & $1.09(0.99$ to 1.20$)$ & 1.17 (1.06 to 1.30$)$ \\
\hline Multivariableł (primary+lipids) & $1.17(1.06$ to 1.29$)$ & $1.06(0.98$ to 1.15$)$ & 1.00 & 1.07 (0.99 to 1.16$)$ & $1.05(0.96$ to 1.15$)$ & $1.24(1.13$ to 1.36$)$ \\
\hline \multicolumn{7}{|c|}{ 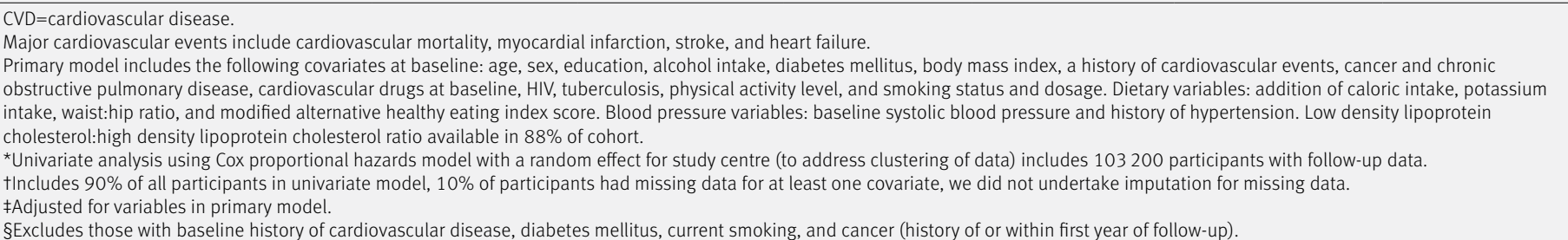 } \\
\hline
\end{tabular}




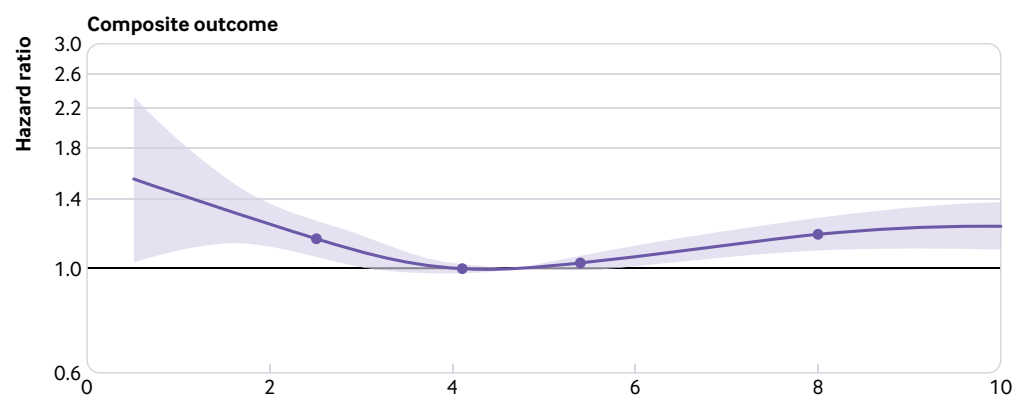

Estimated 24 hour sodium excretion (g/day)
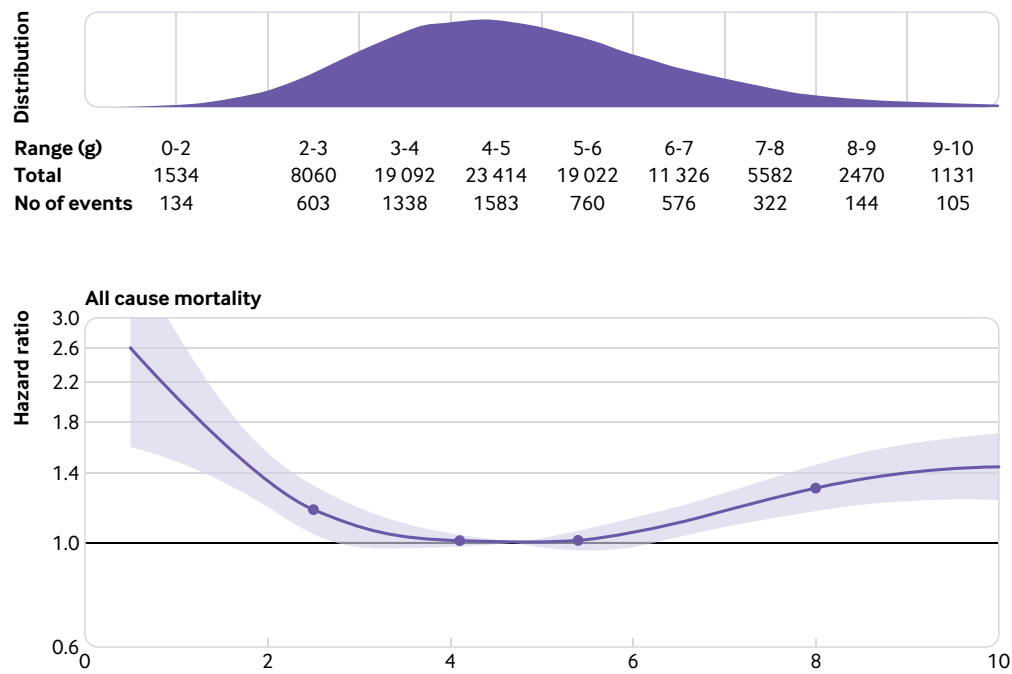

Estimated 24 hour sodium excretion (g/day)
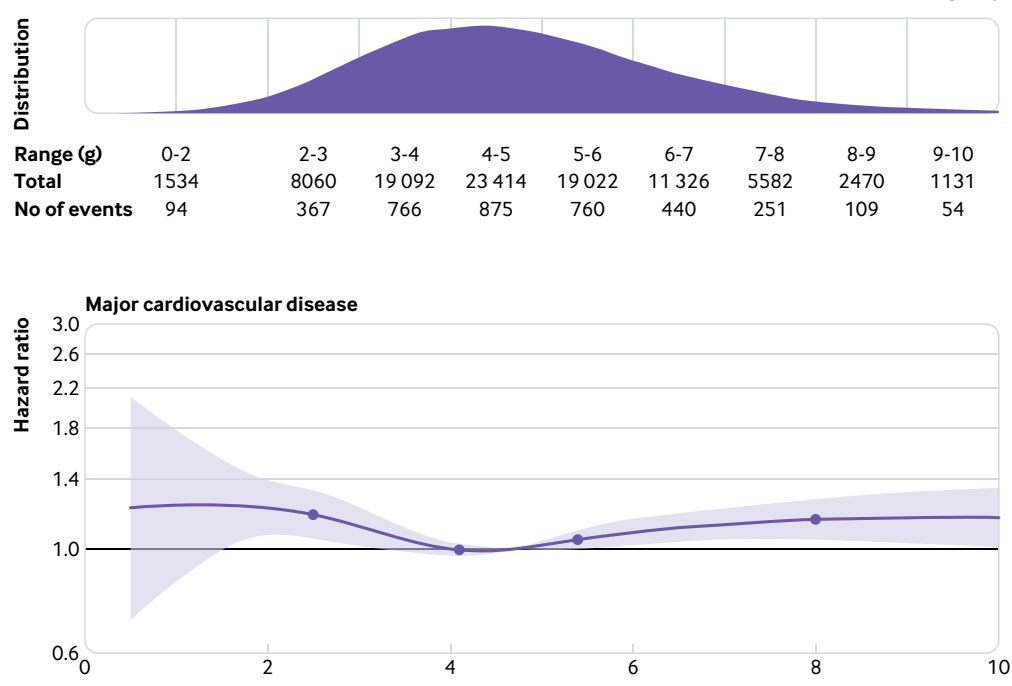

Estimated 24 hour sodium excretion (g/day)

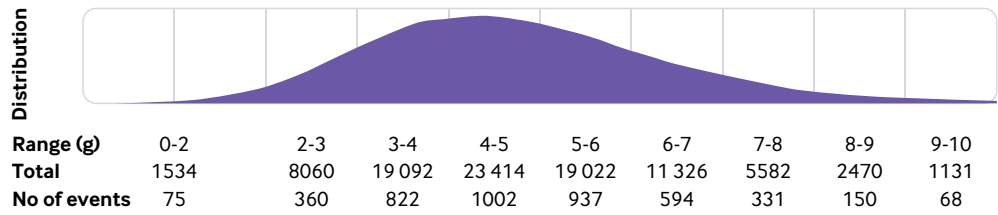

Fig 1 | Restricted cubic spline plot of association of estimated 24 hour urinary sodium excretion with composite of all cause mortality and major cardiovascular events, mortality, and major cardiovascular events (composite of cardiovascular death or myocardial infarction or stroke or heart failure). Plots adjusted for age (included as spline function), sex, education, current and former alcohol intake (units weekly), diabetes mellitus, body mass index, physical activity, history of cardiovascular events, use of cardiovascular drugs (blood pressure lowering, statins, or antidiabetics), history of tuberculosis, cancer, HIV, and current and former smoking. Dashed lines indicate $95 \%$ confidence intervals. Median intake is reference standard ( $4.9 \mathrm{~g} / \mathrm{day})$. Salt approximates $2.5 \times$ sodium $\mathrm{g} /$ day. Spline curve was truncated at $10 \mathrm{~g} /$ day in all plots 

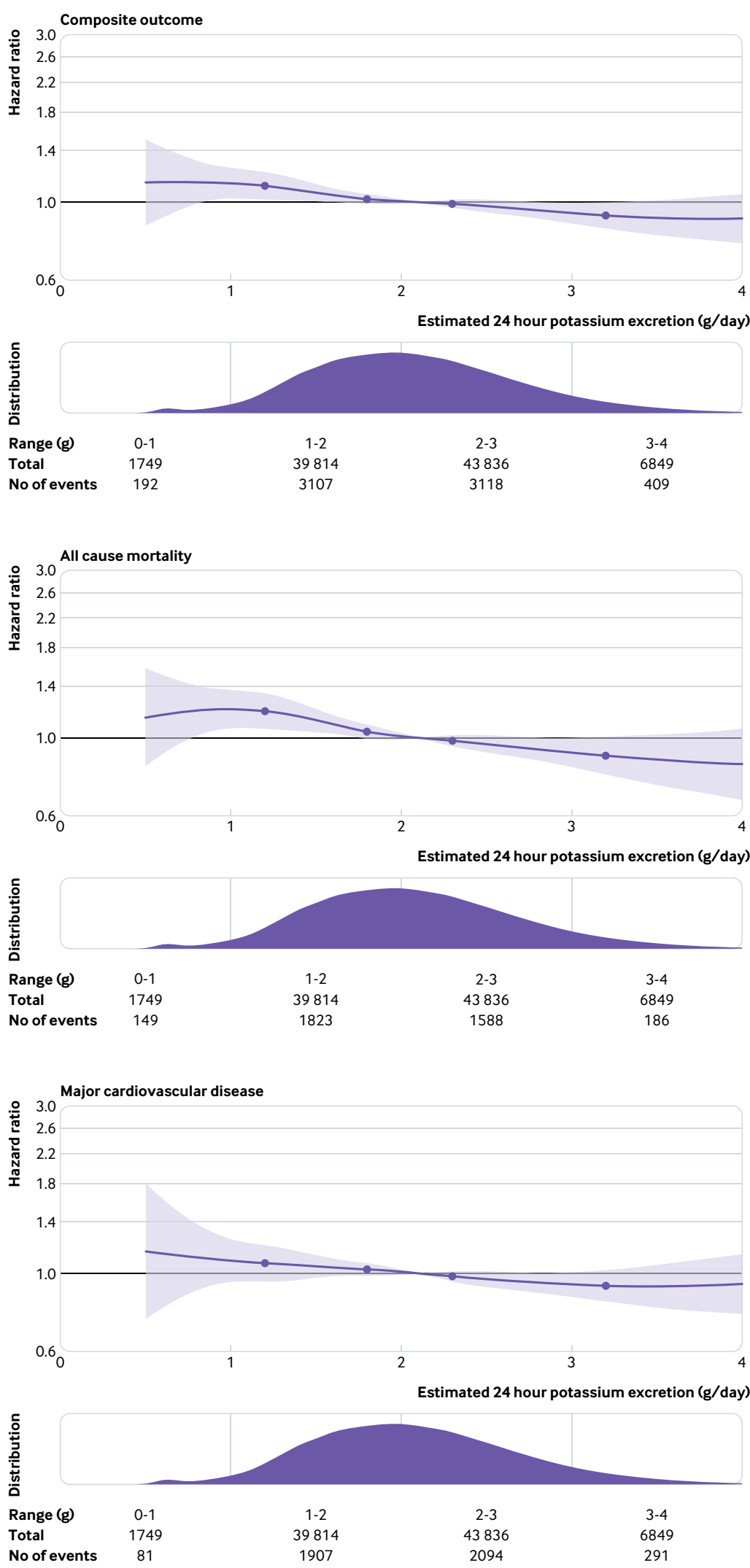

Fig 2 | Restricted cubic spline plot of association of estimated 24 hour urinary potassium excretion with composite of all cause mortality and major cardiovascular events, mortality, and major cardiovascular events (composite of cardiovascular death, myocardial infarction, stroke, and heart failure). Plots adjusted for age (included as spline function), sex, education, current and former alcohol intake (units weekly), diabetes mellitus, body mass index, physical activity, history of cardiovascular events, use of cardiovascular drugs (blood pressure lowering, statins, or antidiabetics), history of tuberculosis, cancer, HIV, and current and former smoking. Spline was truncated at $4 \mathrm{~g} / \mathrm{day}$ in all plots 


\begin{tabular}{|c|c|c|c|}
\hline \multirow[b]{2}{*}{ Estimated potassium excretion (g/day) } & \multicolumn{3}{|c|}{ Estimated sodium excretion (g/day) } \\
\hline & $<3$ & $3-5$ & $>5$ \\
\hline Hazard ratio $(95 \% \mathrm{Cl})$ & $1.23(1.11$ to 1.37$)$ & $1.10(1.01$ to 1.19$)$ & $1.21(1.11$ to 1.32$)$ \\
\hline Event proportion* & $716 / 7582(9.4 \%)$ & $1924 / 24741(7.8 \%)$ & $1260 / 14259(8.8 \%)$ \\
\hline \multicolumn{4}{|l|}{ zmedian, $2.1 \mathrm{~g} /$ day: } \\
\hline Event proportion* & $233 / 3420(6.8 \%)$ & $1454 / 22688(6.4 \%)$ & $2297 / 30510(7.5 \%)$ \\
\hline \multicolumn{4}{|c|}{$\begin{array}{l}\text { Adjusted for age (included as spline function), sex, education, current and former alcohol intake (units weekly), diabetes mellitus, body mass index, } \\
\text { physical activity, history of cardiovascular events, use of cardiovascular drugs (blood pressure lowering, statins, or antidiabetics), history of tuberculosis } \\
\text { cancer, HIV, and current and former smoking. } \\
\text { *Event proportion for composite outcome of major cardiovascular events or mortality. }\end{array}$} \\
\hline
\end{tabular}

\section{Sensitivity analyses}

Exclusion of participants who had events in the first three years of follow-up, and excluding those with baseline cardiovascular disease, cancer (or cancer in first year of follow-up, diabetes, and current smoking), did not materially affect findings. (table 1) Supplementary figure 1 reports the association of "usual" 24 hour urinary sodium excretion and clinical outcomes.

\section{Discussion}

In this large international prospective cohort study, we investigated the joint association of estimated sodium and potassium urinary excretion (surrogates for intake) and clinical outcomes over a median follow-up of 8.2 years. Overall, the lowest risk of death and adverse clinical events was seen in those with estimated sodium excretion between 3 and $5 \mathrm{~g} /$ day, and with the highest

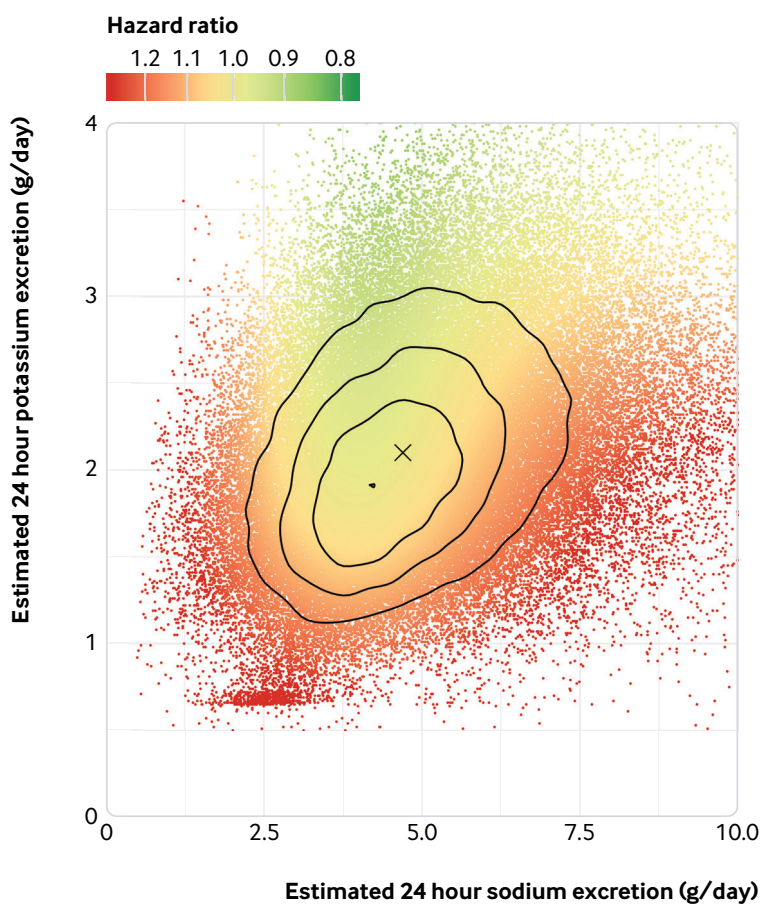

Fig 3 | Heat map of risk for composite of cardiovascular events or death showing lowest risk in region of moderate sodium intake 3-5 g/day and higher potassium intake and highest risk in region of extremes of sodium excretion and low potassium excretion. The reference hazard for these hazard ratios was set at a value of sodium daily excretion/ intake of $5.00 \mathrm{~g}$ and potassium daily excretion/intake of $2.25 \mathrm{~g}$ (median excretion of sodium and potassium), marked as X. The overlaid lines represent joint distribution quartiles; each region contains a quarter of the analysed participants. $r=0.34$ potassium excretions (see fig 1 and table 2). Both higher and lower levels of estimated sodium excretion were associated with higher cardiovascular risk, thereby describing a J-shaped curve for association, whereas the association of potassium excretion and mortality or cardiovascular risk was inverse and linear. Higher potassium intake attenuated the increased cardiovascular risk associated with high sodium intake, and the association of high sodium excretion with cardiovascular risk was most prominent in those with low potassium intake.

\section{Comparison with other studies}

Potassium, the most abundant intracellular cation, and sodium, the most abundant extracellular cation, are inextricably linked, with their exchange required for membrane potential of cells (Na-K-ATPase) and their inter-reliance on diet and kidneys to maintain homeostasis. $^{23}$ We found that the association of higher sodium excretion with cardiovascular risk was lower among those with higher urinary potassium excretion. While previous studies have reported that higher potassium intake diminishes the association of higher sodium intake with increased blood pressure, no study has been sufficiently large to show a statistically significant modifying effect of sodium and potassium intake with cardiovascular events and mortality. ${ }^{19-24}$ In our analyses, extremes of sodium excretion (both high and low) in a setting of low potassium excretion are associated with the highest risk of death and cardiovascular events (see fig 1 and table 2). Low potassium intake not only results in potassium retention by the kidneys, but also induces sodium retention. ${ }^{36}{ }^{37}$ Renal conservation of sodium in the setting of low potassium diets is mediated through WNK ("with no lysine(K)") kinases activating the thiazide sensitive sodium-chloride cotransporter, leading to greater increases in blood pressure with increasing sodium intake. ${ }^{38} 39$ Low potassium intake might also reflect poorer diet quality, particularly lower intake of fruits and vegetables, and the association of sodium intake with cardiovascular risk might be confounded by foods that independently affect cardiovascular risk. Our subgroup analysis by diet quality (modified alternative healthy eating index, mAHEI) would lend some support to this contention, whereby the magnitude of association of sodium excretion with cardiovascular risk appeared 


\begin{tabular}{|c|c|c|c|c|c|c|c|}
\hline \multirow[b]{2}{*}{ Tertiles } & \multicolumn{6}{|c|}{ Estimated sodium excretion (g/day) } & \multirow[b]{2}{*}{ P for interaction } \\
\hline & $<3(n=11002)$ & $3-3.99(n=21417)$ & $4-4.99(n=26012)$ & $5-5.99(n=21093)$ & $6-6.99(n=12458)$ & $\geq 7(n=11218)$ & \\
\hline \multicolumn{8}{|c|}{ Potassium excretion (g/day): } \\
\hline$<1.8$ & $1.14(1.00$ to 1.30$)$ & $1.02(0.91$ to 1.14$)$ & 1.00 & $1.02(0.89$ to 1.16$)$ & $1.15(0.97$ to 1.36$)$ & 1.27 (1.04 to 1.54$)$ & $\begin{array}{l}\mathrm{P}=0.93 \text { («median } \\
\text { sodium excretion) } \\
\mathrm{P}=0.007 \text { (>median } \\
\text { sodium excretion) }\end{array}$ \\
\hline $1.8-2.3$ & $1.16(0.97$ to 1.38$)$ & $1.11(0.97$ to 1.26$)$ & 1.00 & $1.16(1.03$ to 1.31$)$ & $1.17(1.01$ to 1.36$)$ & $1.47(1.26$ to 1.71$)$ & \\
\hline 12.3 & $1.12(0.91$ to 1.39$)$ & $1.02(0.88$ to 1.18$)$ & 1.00 & $1.08(0.95$ to 1.22$)$ & $1.01(0.88$ to 1.16$)$ & $1.11(0.96$ to 1.27$)$ & \\
\hline \multicolumn{8}{|c|}{ Modified alternative healthy eating index score: } \\
\hline$<31.3$ & $1.18(1.01$ to 1.38$)$ & $1.10(0.97$ to 1.25$)$ & 1.00 & $1.11(0.98$ to 1.25$)$ & 1.07 (0.92 to 1.25$)$ & $1.47(1.26$ to 1.73$)$ & $\begin{array}{l}\mathrm{P}=0.87 \text { ( } \text { median } \\
\text { sodium excretion) } \\
\mathrm{P}=0.30 \text { (>median } \\
\text { sodium excretion) }\end{array}$ \\
\hline 31.3-38.4 & $1.24(1.06$ to 1.46$)$ & $1.09(0.96$ to 1.25$)$ & 1.00 & $1.14(1.01$ to 1.30$)$ & $1.12(0.97$ to 1.30$)$ & $1.22(1.05$ to 1.43$)$ & \\
\hline$>38.4$ & $1.09(0.92$ to 1.29$)$ & $1.03(0.90$ to 1.17$)$ & 1.00 & $1.00(0.88$ to 1.14$)$ & $0.99(0.85$ to 1.14$)$ & 1.06 (0.91 to 1.23$)$ & \\
\hline
\end{tabular}

Adjusted for age (included as spline function), sex, education, current and former alcohol intake (units per week), diabetes mellitus, body mass index, physical activity, history of cardiovascular events, use of cardiovascular medications (blood pressure lowering, statins, or antidiabetics), history of tuberculosis, cancer, HIV, and current and former smoking.

lower among those consuming the highest third of diet quality, although formal tests of interaction were not statistically significant (table 3). Therefore, higher potassium intake could directly affect cardiovascular and mortality risks or is a marker of increased intake of healthier food items that are rich in potassium (eg, fruit, vegetables, nuts), or a combination of both. The DASH-Sodium trial reported a lower antihypertensive effect of reducing sodium intake, in the setting of higher potassium intake, supporting the contention that the association of higher sodium intake with cardiovascular health might be modified by potassium intake. $^{40} \mathrm{~A}$ small cluster randomised controlled trial (five centres), which replaced table salt with low sodium salt substitute (partially replaced with potassium chloride) reported a reduced cardiovascular risk in those centres randomised to salt substitution, although findings were not conclusive owing to methodological limitations of the trial. ${ }^{41}$ An ongoing large cluster randomised controlled trial in China, evaluating the use of salt substitutes (potassium chloride substituted for sodium chloride) is expected to provide a more definitive answer. ${ }^{42}$ However, these trials evaluate simultaneous increased potassium intake with a reduction of high sodium intake to moderate intake levels, and it is unlikely to inform whether a very low sodium intake $(<2.0 \mathrm{~g} /$ day $)$ is beneficial or harmful. Finally, increased cardiovascular risk might also be mediated through activation of numerous adaptive renal and neuroendocrine mechanisms to maintain balance of both electrolytes, in response to low potassium and low dietary sodium, especially activation of the renin-aldosteroneangiotensin system, ${ }^{18}$ the activation of which is known to increase cardiovascular risk. Collectively, these data suggest that the health impact of these two cations cannot be easily assessed separately. However, our findings would argue against an isolated use of a sodium:potassium ratio, because of the J-shaped association of sodium intake and clinical outcomes and the ratio does not take account of absolute intake levels. For example, the combination of moderate intake of sodium and potassium is associated with lower cardiovascular risk than combined low intake of both sodium and potassium, despite the same sodium:potassium ratio.

\section{Public health implications}

Guidelines for dietary recommendations, targeting the entire population, should be both feasible and based on clear high quality evidence of improved health outcomes. $^{45}$ Our results suggest that a combined strategy of low sodium intake $(<2.0 \mathrm{~g} / \mathrm{day})$, while simultaneously increasing potassium intake to $>3.5 \mathrm{~g} /$ day, is unrealistic, as only $0.002 \%$ of the population were in this range $(0.2 \%$ for potassium excretion of $2.62 \mathrm{~g} /$ day, if we assume that about $75 \%$ of potassium is excreted in urine ${ }^{35}$ ). These estimates are consistent with reports from studies in the United Kingdom $(0.1 \%)$, United States $(0.3 \%)$, Mexico $(0.15 \%)$, and France $(0.5 \%){ }^{7}$ In each of these studies, estimates of sodium intake were based on questionnaire, which is known to underestimate intake, meaning that the proportion of the population achieving actual target may be lower than reported. ${ }^{7}$ This finding also meant that we were unable to evaluate the association of these joint dietary intake levels with health outcomes, as numbers of participants were insufficient despite the large sample size. We observed a linear relation between increased sodium and potassium intake, a consistent finding of other studies. ${ }^{70}$ These findings question the feasibility of increasing potassium intake while achieving very low sodium intake of populations through modifying diets. While small phase II clinical trials, such as DASH-Sodium, ${ }^{40}$ have achieved these targets in the short term, they required complete control of dietary intake, which is impractical in free living populations. In contrast, the PREDIMED study, ${ }^{43}$ which promoted increased intake of potassium containing foods (fruit, vegetables, nuts) with greater adherence to the Mediterranean diet, without focusing on low sodium intake, reported a statistically significant reduction in cardiovascular disease and mortality, and adherence to a Mediterranean diet has 

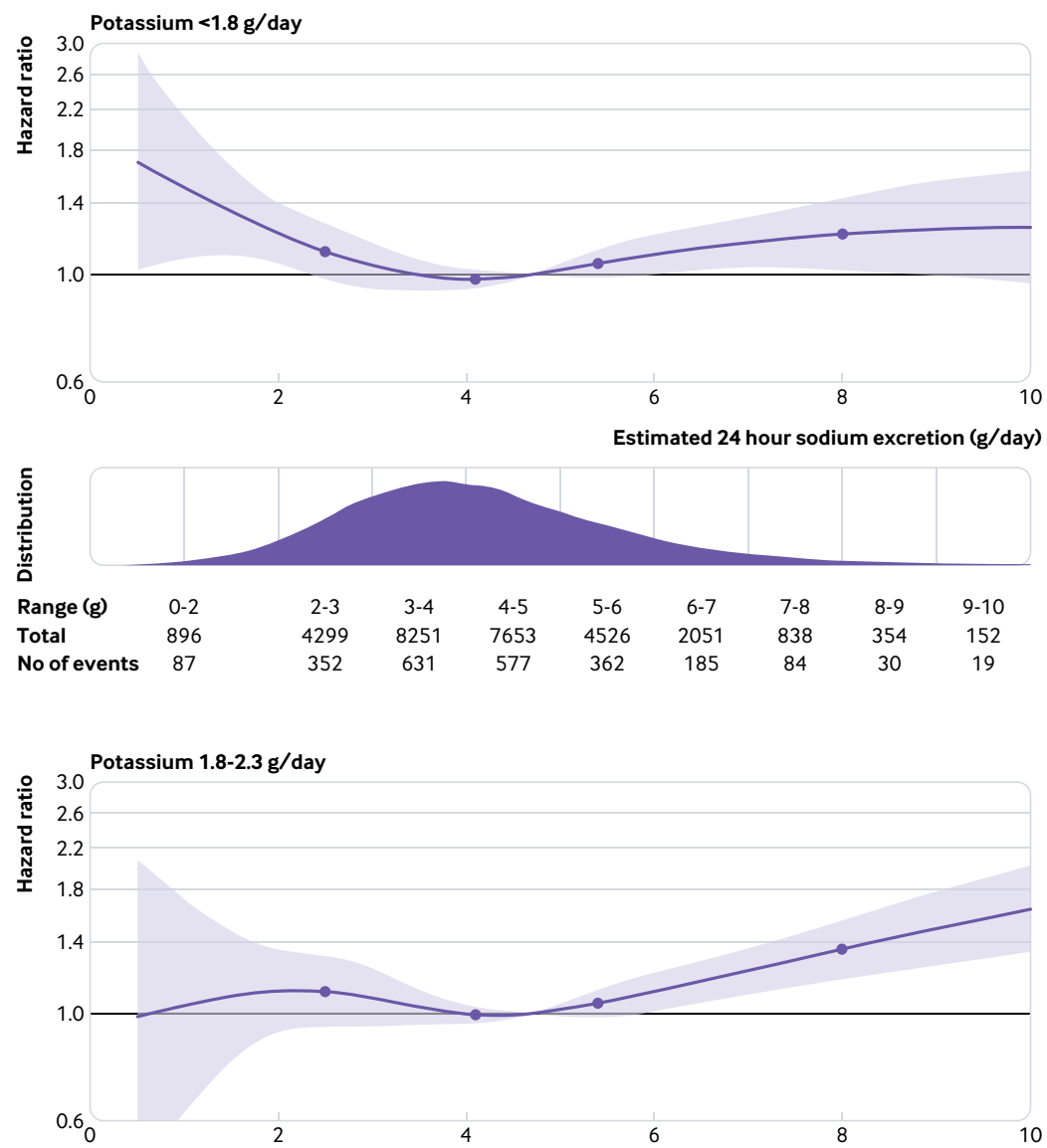

Estimated 24 hour sodium excretion (g/day)
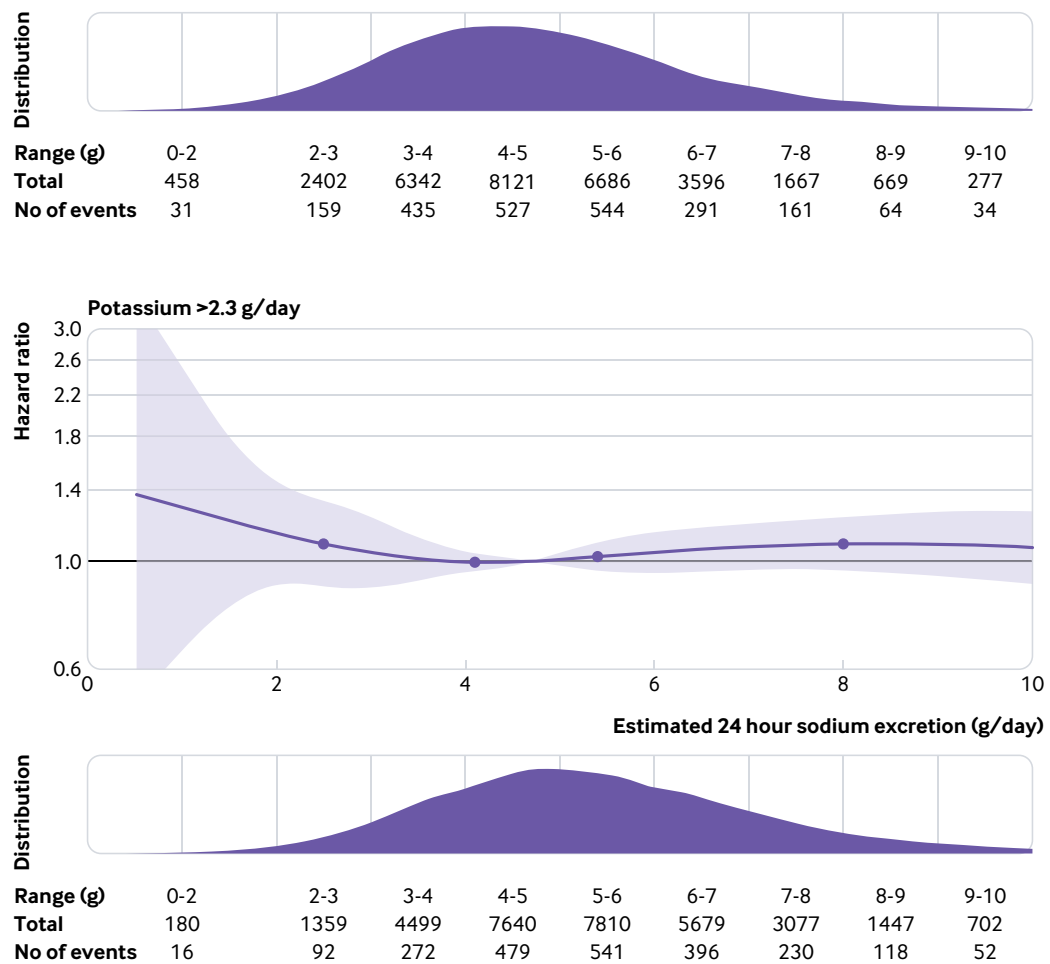

Fig 4 | Association of urinary sodium excretion within tertiles of urinary potassium excretion. $P$ for interaction is significant $(P=0.007)$ for urinary potassium excretion $x$ urinary sodium excretion above median intake, with lower magnitude of association with higher urinary potassium excretion. Plots adjusted for age (included as spline function), sex, education, current and former alcohol intake (units weekly), diabetes mellitus, body mass index, physical activity, history of cardiovascular events, use of cardiovascular drugs (blood pressure lowering, statins, or antidiabetics), history of tuberculosis, cancer, HIV, and current and former smoking 

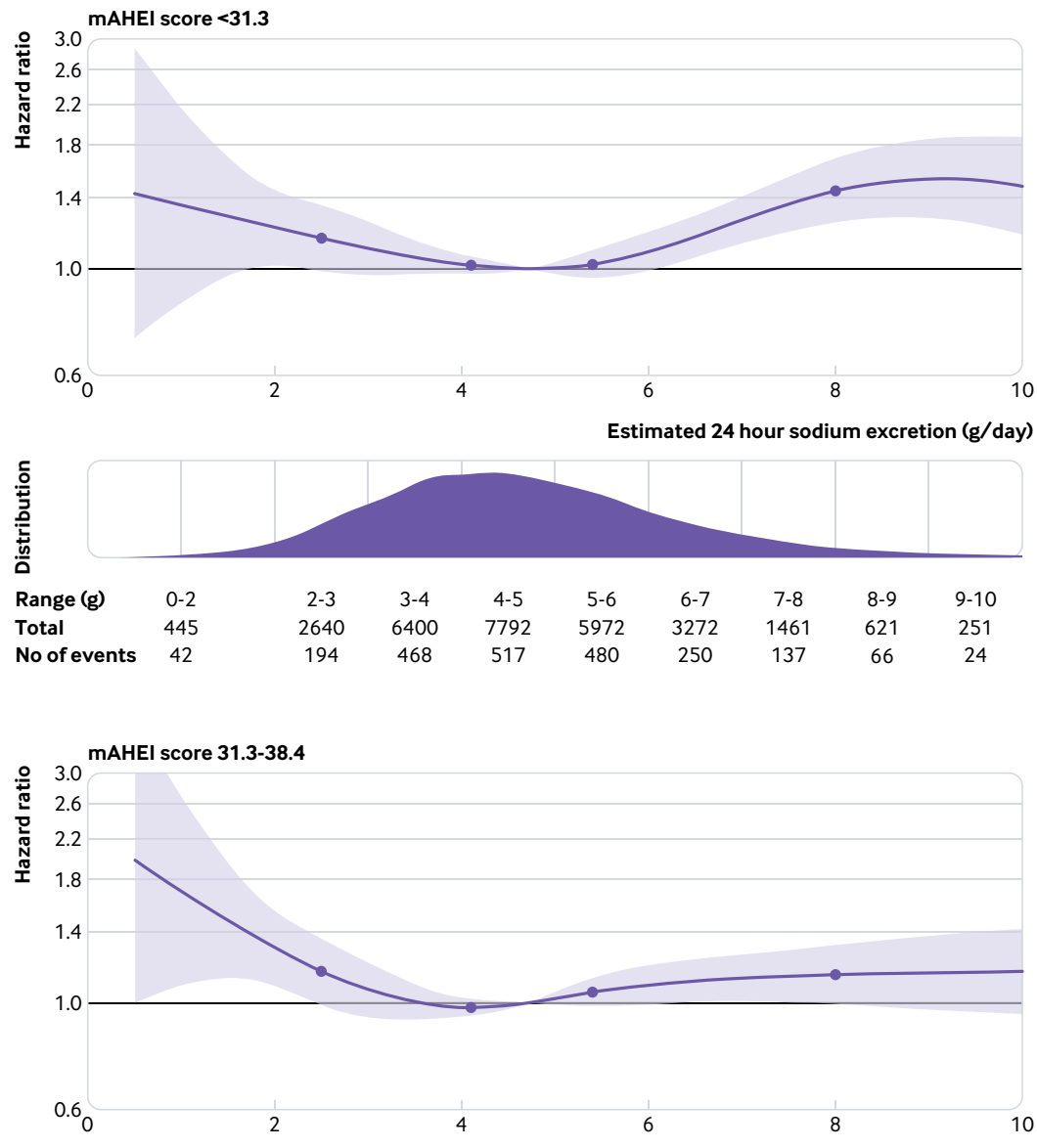

Estimated 24 hour sodium excretion (g/day)
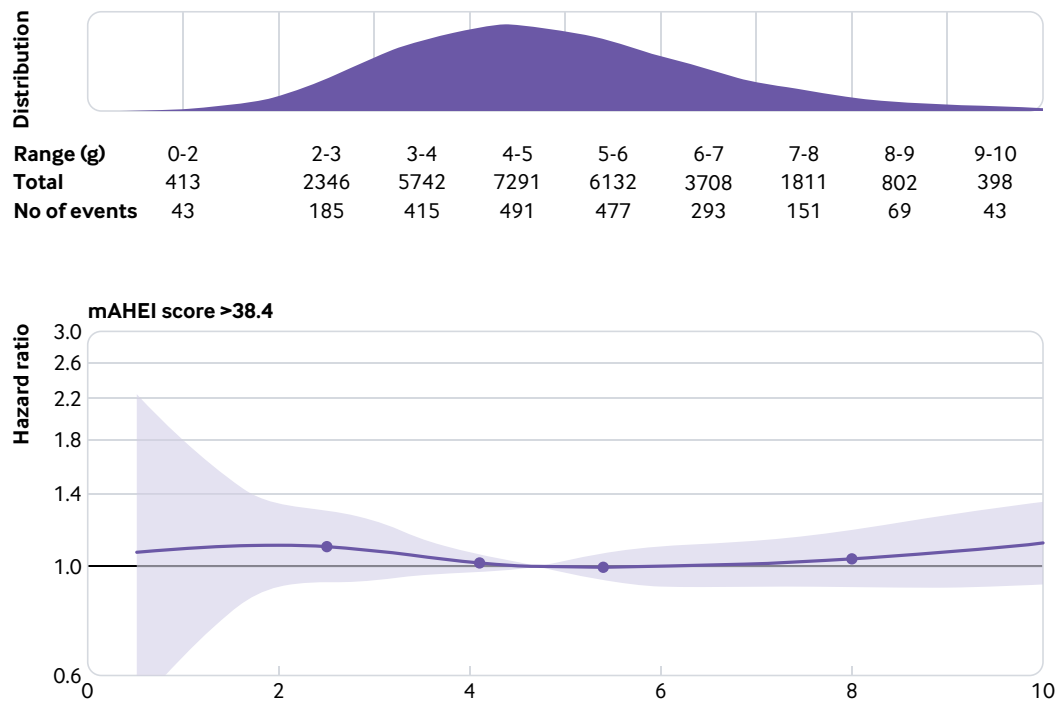

Estimated 24 hour sodium excretion (g/day)

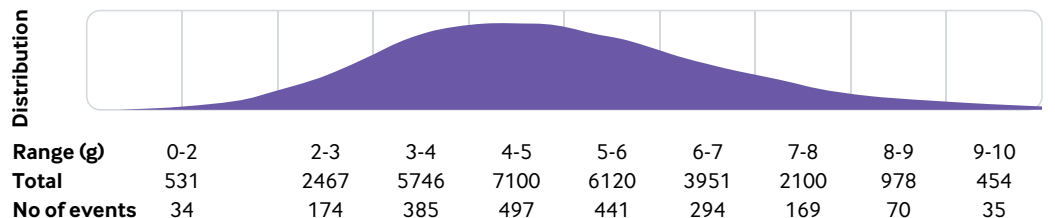

Fig 5 | Association of urinary sodium excretion within tertiles of modified alternative healthy eating index (mAHEI) score. P for interactions not significant. Plots adjusted for age (included as spline function), sex, education, current and former alcohol intake (units weekly), diabetes mellitus, body mass index, physical activity, history of cardiovascular events, use of cardiovascular drugs (blood pressure lowering, statins, or antidiabetics), history of tuberculosis, cancer, HIV, and current and former smoking 
an inconsistent correlation with sodium intake. ${ }^{44} 45$ In addition, a recent analysis of the NHANES study reported that sodium intake $>2.3 \mathrm{~g} /$ day was associated with better diet quality, compared with diets of less than $2.3 \mathrm{~g} /$ day, meaning that improving dietary quality is likely to be easier to achieve within a moderate sodium intake range. ${ }^{46}$ These considerations raise considerable doubts about the feasibility and assumed cardiovascular effects of current recommendations to reduce sodium intake to very low levels ( $<2 \mathrm{~g} /$ day $)$, which may counteract achieving other dietary targets and improving overall dietary quality.

\section{Strengths and limitations of this study}

Our estimate of sodium intake was based on a baseline measurement of sodium intake, derived from fasting morning urine samples, rather than repeated 24 hour urinary collections, which would be considered the reference standard for estimating usual sodium and potassium intake. However, our approach has been validated in an international study, against actual 24 hour urine estimates of sodium and potassium excretion. ${ }^{31}$ Other formula based approaches have been developed for estimating 24 hour urinary sodium and potassium excretion, and one study reported that the Kawasaki formula was associated with the largest bias compared with actual 24 hour urine collections. In that study by Cogswell et $\mathrm{al},{ }^{47}$ however, a nonfasting spot urine sample was used, which would be expected to produce biased over-estimates since the Kawasaki formula was developed and validated for a fasting urine sample, best reflecting basal excretion. In another study, ${ }^{48}$ which used an appropriate fasting sample, the Kawasaki formula approach was reported to be associated with least biased estimates (versus other formula) compared with actual 24 hour urine. Further evidence of the construct validity of our approach is the relation of estimated 24 hour urine estimates of sodium excretion to blood pressure (2.11/0.78 $\mathrm{mm} \mathrm{Hg} / \mathrm{g}$ increase in estimated 24 hour urinary sodium excretion), which are consistent with estimates reported in randomised controlled trials of sodium reduction..$^{25}$

Relating a single time-point estimate of sodium and potassium intake to long term follow-up of death and cardiovascular events might be problematic if there are interval changes in dietary intake over time, and where repeated dietary measures are required to reduce the risk of regression dilution bias. Our approach is consistent with many other large epidemiological studies of sodium and potassium intake and analogous to epidemiological studies relating blood pressure, glucose, and cholesterol to clinical outcomes. For example, the correlation of office blood pressure and 24 hour ambulatory blood pressure and of fasting glucose to glycated haemoglobin (HbA1c), is similar to the correlation we report for formula derived estimates. $^{31}$ We chose this practical approach to estimating population level sodium and potassium intake in the PURE study, which includes a large representative population of participants from high, middle, and low income countries. We deemed actual 24 hour collections to be unfeasible in many low income settings and expected to have a greater risk selection bias due to non-completion of 24 hour collections. For example, in a recent NHANES study, ${ }^{49}$ completion rates for 24 hour urine samples were about $75 \%$, and completers differed from non-completed for age, sex, ethnicity, body mass index, and hypertension status. For these reasons, WHO suggests ${ }^{50}$ the use of formula derived estimates of sodium and potassium intake in population level studies monitoring intakes over time. Among studies reporting on temporal changes of sodium intake over time, there is stability in mean intake of countries, ${ }^{651}$ especially those with mean sodium intake in the moderate range (3-5 g/day), whereas some countries with high mean intakes ( $>5 \mathrm{~g} /$ day) have reported reductions in mean intake levels (eg, China, Finland), ${ }^{52}$ which means that interval changes in sodium intake are less likely to influence our findings in the low to moderate range of sodium intake but could reduce the magnitude of association in the higher sodium intake range.

Reverse causation has been a criticism of prospective cohort studies evaluating the association of diet and clinical outcomes, which may also occur when people reduce their sodium intake because of illness or based on medical recommendations. Alternatively, it may occur when people with a history of cardiovascular disease or risk factors, who are at increased cardiovascular risk, reduce their sodium intake on medical recommendations. In the PURE study, a few participants had previous cardiovascular disease, and our findings were not materially altered with their exclusion. Moreover, in the current analyses the exclusion of participants with cancer or diabetes or who were current smokers or those who had events in the first three years of follow-up did not materially alter findings. Additionally, we did not find an increased risk of death due to cancer with low sodium intake. Finally, given the observational nature of the study, residual confounding is a potential limitation. However, we adjusted for all major confounders of the association between sodium and potassium intake and cardiovascular events. Strengths of our study include the large representative international population in the PURE study, completeness of follow-up, rigorous approach to measurement of baseline variables, and adjudicated outcome clinical events.

\section{Conclusions}

Our findings suggest that a simultaneous target of low sodium $(<2 \mathrm{~g} /$ day $)$ with high potassium intake $(>3.5$ $\mathrm{g} /$ day) in the population is extremely uncommon. The combination of moderate sodium intake (3-5 g/ day) with high potassium intake is associated with the lowest risk of mortality and cardiovascular events, whereas extremes of sodium intake combined with low potassium urinary excretion were associated with the highest cardiovascular risk. Our data support population wide increases in dietary potassium intake, with a population specific (ie, sodium intakes $>5 \mathrm{~g} /$ 
day) reduction of sodium intake, embedded within an overall healthy dietary pattern.

\section{AUTHOR AFFILIATIONS}

${ }^{1}$ Population Health Research Institute, DBCVS Research Institute, McMaster University, 237 Barton St East, Hamilton, ON L8L 2X2. Canada

${ }^{2}$ HRB-Clinical Research Facility, Galway University Hospital, NUI Galway, Galway, Ireland

${ }^{3}$ Medical Research \& Biometrics Centre, National Centre for Cardiovascular Diseases Cardiovascular, Fengcunxili, Mentougou District, Beijing, China

${ }^{4}$ Division of Nutrition, St John's Research Institute, Bangalore, Karnataka, India

${ }^{5}$ Departments of Neurology, Northwestern University Feinberg School of Medicine, Chicago, IL, USA

${ }^{6}$ Sahlgrenska Academy, University of Gothenburg, and Region Västra Götaland, Sahlgrenska University Hospital, Gothenburg, Sweden

${ }^{7}$ Fundacion Oftalmologica de Santander (FOSCAL), Medical School, Universidad de Santander, Floridablanca-Santander, Colombia

${ }^{8}$ Estudios Clinicos Latinoamerica ECLA, Instituto Cardiovascular de Rosario, Rosario, Santa Fe, Argentina

${ }^{9}$ Dante Pazzanese Institute of Cardiology, Sao Paulo, Brazil

${ }^{10}$ Universidad de La Frontera, Temuco, Chile

${ }^{11}$ Department of Community Health. University Kebangsaan Malaysia Medical Centre, Malaysia

${ }^{12}$ Faculty of Medicine and Health Sciences, UCSI University, Kuala Lumpur, Malaysia

${ }^{13}$ University of the Philippines-Manila, Ermita, Manila, Philippines

${ }^{14}$ Departments of Community Health Sciences and Medicine, Aga Khan University, Karachi, Pakistan

${ }^{15}$ Division of Angiology, Wroclaw Medical University, Wroclaw, Poland

${ }^{16}$ Isfahan Cardiovascular Research Centre, Cardiovascular Research Institute, Isfahan University of Medical Sciences, Isfahan, Iran

${ }^{17}$ Istanbul Medeniyet University, Faculty of Medicine, Department of Internal Medicine, Istanbul, Turkey

${ }^{18}$ Hatta Hospital, Dubai Medical University, Dubai Health Authority. Dubai, United Arab Emirates

${ }^{19}$ Department of Cardiac Sciences, King Fahad Cardiac Centre, College of Medicine, King Saud University. Riyadh, Saudi Arabia

${ }^{20}$ Faculty of Health Science, North-West University, Potchefstroom campus, Potchefstroom, South Africa

${ }^{21}$ School of Life Sciences and The Centre for Health, Population and Development. Independent University, Bangladesh, Dhaka, Bangladesh

${ }^{22}$ University of Zimbabwe, College of Health Sciences, Physiology Department, Harare, Zimbabwe

${ }^{23}$ Department of Medicine, Division of Nephrology, Queen's University, Kingston, Canada

${ }^{24}$ Laval University Heart and Lungs Institute, Quebec City, QC, Canada

${ }^{25}$ Faculty of Medicine, University of Ottawa, Ottawa, ON, Canada

${ }^{26}$ Faculty of Health Sciences, Simon Fraser University, and Division of Cardiology, Providence Health Care, BC, Canada

Contributors: SY conceived and started the overall Prospective Urban Rural Epidemiology (PURE) study. SR coordinated the study. KT was the co-principal investigator. MOD, SY, and AM designed the study. SY supervised the study. NOL and JF did the statistical analysis. MOD, SY, and AM wrote the first draft of the manuscript. SY supervised the study conduct and data analysis and provided critical comments on all drafts of the manuscript. All other authors coordinated the study and collected the data in their respective countries and provided comments on drafts of the manuscript. All authors reviewed and provided critical comments on drafts. All authors have approved the submitted version. The corresponding author attests that all listed authors meet authorship criteria and that no others meeting the criteria have been omitted.

Funding: The funders of the study had no role in its design or conduct, in the collection, analysis, or interpretation of the data, or in the writing of the manuscript. The current analyses were supported by funding from the European Research Council (COSIP grant, 640580) and Heart and Stroke Foundation of Ontario. SY is supported by the Mary W Burke endowed chair of the Heart and Stroke Foundation of Ontario. The PURE study is an investigator initiated study that is funded by the Population Health Research Institute, the Canadian Institutes of Health Research, Heart and Stroke Foundation of Ontario, Support from CIHR's Strategy for Patient Oriented Research, through the Ontario SPOR Support Unit, as well as the Ontario Ministry of Health and Long-Term Care and through unrestricted grants from several pharmaceutical companies (with major contributions from Astra Zeneca (Canada), Sanofi-Aventis (France and Canada), Boehringer Ingelheim (Germany and Canada), Servier, and GSK), and additional contributions from Novartis and King Pharma and from various national or local organisations in participating countries. These include Argentina: Fundacion ECLA; Bangladesh: Independent University, Bangladesh and Mitra and Associates; Brazil: Unilever Health Institute, Brazil; Canada: Public Health Agency of Canada and Champlain Cardiovascular Disease Prevention Network, Canadian Institutes of Health Research (Catalyst Grant: eHealth Innovations-grant No: 126524); Chile: Universidad de La Frontera (Internal Registry DI13-PE11); China: National Center for Cardiovascular Diseases; Colombia: Colciencias, grant No:656604-18062; India: Indian Council of Medical Research; Malaysia: Ministry of Science, Technology and Innovation of Malaysia grant No 100-IRDC/BIOTEK 16/6/21 (13/2007), grant No 07-05-IFN-BPH 010, Ministry of Higher Education of Malaysia grant No 600-RMI/ LRGS/5/3 (2/2011), Universiti Teknologi MARA, Faculty of Medicine, Universiti Kebangsaan Malaysia, Kuala Lumpur Malaysia. CRIM, University Kebangsaan Malaysia; Occupied Palestinian Territory: The United Nations Relief and Works Agency for Palestine Refugees in the Near East (UNRWA), occupied Palestinian territory; International Development Research Centre (IDRC), Canada; Peru: National Heart, Lung and Blood Institute (HHSN268200900033C), National Cancer Institute (1P20CA217231), Wellcome (103994/Z/14/Z); Philippines: Philippine Council for Health Research \& Development (PCHRD); Poland: Polish Ministry of Science and Higher Education grant No 290/W-PURE/2008/0, Wroclaw Medical University, Wroclaw Medical University, statutory activity Saudi Arabia: Saudi Heart Association, The Deanship of Scientific Research at King Saud University, Riyadh, Saudi Arabia (Research group No: RG -1436-013); South Africa: The North-West University, SANPAD (SA and Netherlands Programme for Alternative Development), National Research Foundation, Medical Research Council of SA. The SA Sugar Association (SASA), Faculty of Community and Health Sciences (UWC); Sweden: grants from the Swedish state under the Agreement concerning research and education of doctors; the Swedish Heart and Lung Foundation; the Swedish Research Council; the Swedish Council for Health, Working Life and Welfare, King Gustaf V:s and Queen Victoria Freemason's Foundation, AFA Insurance; Tanzania: Pamoja Tunaweza Health Research Centre (Tanzania), Queen's University, Department of Medicine; Turkey: Metabolic Syndrome Society, Astra Zeneca, Turkey; UAE: Sheikh Hamdan Bin Rashid Al Maktoum Award for Medical Sciences, and Dubai Health Authority, Dubai UAE.

Competing interests: All authors have completed the ICMJE uniform disclosure form at www.icmje.org/coi_disclosure.pdf and declare: no support from any additional organisation for the submitted work. A detailed list of funders is provided in the supplementary appendix. The authors have no financial relationships with any organisations, or other relationships or activities, that might have influenced the submitted work in the previous three years.

Ethical approval: This study was approved by the research ethics committees at all participating centres and at Hamilton Health Sciences, Hamilton, Ontario, Canada.

Data sharing: No additional data available.

Transparency: The lead author (MO'D) affirms that the manuscript is an honest, accurate, and transparent account of the study being reported; that no important aspects of the study have been omitted and that any discrepancies from the study as planned have been explained.

This is an Open Access article distributed in accordance with the Creative Commons Attribution Non Commercial (CC BY-NC 4.0) license, which permits others to distribute, remix, adapt, build upon this work non-commercially, and license their derivative works on different terms, provided the original work is properly cited and the use is noncommercial. See: http://creativecommons.org/licenses/by-nc/4.0/.

1 Morris RCJr, Schmidlin O, Frassetto LA, Sebastian A. Relationship and interaction between sodium and potassium. J Am Coll Nutr 2006;25(Suppl):262S-70S. doi:10.1080/07315724.2006.10719576 
2 Kotchen TA, Cowley AWJr, Frohlich ED. Salt in health and disease--a delicate balance. N Engl / Med 2013;368:1229-37. doi:10.1056/ NEJMra1212606

3 Palmer BF. Regulation of Potassium Homeostasis. Clin J Am Soc Nephrol 2015;10:1050-60. doi:10.2215/CJN.08580813

4 World Health Organization. Guideline: Sodium Intake for Adults and Children. WHO. 2012 ISBN 9789241504836

5 World Health Organization. Guideline: Potassium Intake for Adults and Children. WHO. 2012 ISBN 9789241504829.

6 Powles J, Fahimi S, Micha R, et al, Global Burden of Diseases Nutrition and Chronic Diseases Expert Group (NutriCoDE). Global, regional and national sodium intakes in 1990 and 2010: a systematic analysis of $24 \mathrm{~h}$ urinary sodium excretion and dietary surveys worldwide. BMJ Open 2013;3:e003733. doi:10.1136/ bmjopen-2013-003733

7 Drewnowski A, Rehm CD, Maillot M, Mendoza A, Monsivais P. The feasibility of meeting the WHO guidelines for sodium and potassium a cross-national comparison study. BMJ Open 2015;5:e006625. doi:10.1136/bmiopen-2014-006625

8 Aburto NJ, Ziolkovska A, Hooper L, Elliott P, Cappuccio FP, Meerpohl JJ. Effect of lower sodium intake on health: systematic review and metaanalyses. BM/ 2013;346:f1326. doi:10.1136/bmj.f1326

9 Aburto NJ, Hanson S, Gutierrez H, Hooper L, Elliott P, Cappuccio FP. Effect of increased potassium intake on cardiovascular risk factors and disease: systematic review and meta-analyses. BM/ 2013:346:f1378, doi:10.1136/bmj.f1378

10 Graudal N, Jürgens G, Baslund B, Alderman MH. Compared with usual sodium intake, low- and excessive-sodium diets are associated with increased mortality: a meta-analysis. Am J Hypertens 2014;27:112937. doi:10.1093/ajh/hpu028

11 Pfister R, Michels G, Sharp SJ, Luben R, Wareham NJ, Khaw KT. Estimated urinary sodium excretion and risk of heart failure in men and women in the EPIC-Norfolk study. Eur J Heart Fail 2014;16:394402. doi:10.1002/ejhf.56

12 Stolarz-Skrzypek K, Kuznetsova T, Thijs L, et al, European Project on Genes in Hypertension (EPOGH) Investigators. Fatal and nonfatal outcomes, incidence of hypertension, and blood pressure changes in relation to urinary sodium excretion. JAMA 2011;305:1777-85. doi:10.1001/jama.2011.574

13 O'Donnell MJ, Yusuf S, Mente A, et al. Urinary sodium and potassium excretion and risk of cardiovascular events. JAMA 2011;306:222938. doi:10.1001/jama.2011.1729

14 Thomas MC, Moran J, Forsblom C, et al, FinnDiane Study Group. The association between dietary sodium intake, ESRD, and all-cause mortality in patients with type 1 diabetes. Diabetes Care 2011;34:861-6. doi:10.2337/dc10-1722

15 Ekinci El, Clarke S, Thomas MC, et al. Dietary salt intake and mortality in patients with type 2 diabetes. Diabetes Care 2011;34:703-9. doi:10.2337/dc10-1723

16 O’Donnell M, Mente A, Rangarajan S, et al, PURE Investigators. Urinary sodium and potassium excretion, mortality, and cardiovascular events. N Engl / Med 2014;371:612-23. doi:10.1056/NEJMoa1311889

17 Mente A, O'Donnell M, Rangarajan S, et al, PURE, EPIDREAM and ONTARGET/TRANSCEND Investigators. Associations of urinary sodium excretion with cardiovascular events in individuals with and without hypertension: a pooled analysis of data from four studies. Lancet 2016;388:465-75. doi:10.1016/S0140-6736(16)30467-6

18 Graudal NA, Hubeck-Graudal T, Jurgens G. Effects of low sodium diet versus high sodium diet on blood pressure, renin, aldosterone, catecholamines, cholesterol, and triglyceride. Cochrane Database Syst Rev 2017;4:CD004022.

19 Binia A, Jaeger J, Hu Y, Singh A, Zimmermann D. Daily potassium intake and sodium-to-potassium ratio in the reduction of blood pressure: a meta-analysis of randomized controlled trials. J Hypertens 2015;33:1509-20. doi:10.1097/ HJH.0000000000000611

20 Cook NR, Obarzanek E, Cutler JA, et al, Trials of Hypertension Prevention Collaborative Research Group. Joint effects of sodium and potassium intake on subsequent cardiovascular disease: the Trials of Hypertension Prevention follow-up study. Arch Intern Med 2009;169:32-40. doi:10.1001/archinternmed.2008.523

21 Geleijnse JM, Witteman JC, Stijnen T, Kloos MW, Hofman A, Grobbee DE. Sodium and potassium intake and risk of cardiovascular events and all-cause mortality: the Rotterdam Study. Eur J Epidemiol 2007;22:763-70. doi:10.1007/s10654-007-9186-2

22 Okayama A, Okuda N, Miura K, et al, NIPPON DATA80 Research Group. Dietary sodium-to-potassium ratio as a risk factor for stroke, cardiovascular disease and all-cause mortality in Japan: the NIPPON DATA80 cohort study. BMJ Open 2016;6:e011632. doi:10.1136/ bmjopen-2016-011632

23 Willey J, Gardener H, Cespedes S, Cheung YK, Sacco RL, Elkind MSV. Dietary Sodium to Potassium Ratio and Risk of Stroke in a Multiethnic Urban Population: The Northern Manhattan Study. Stroke 2017;48:2979-83. doi:10.1161/STROKEAHA.117.017963
24 Yang Q, Liu T, Kuklina EV, et al. Sodium and potassium intake and mortality among US adults: prospective data from the Third National Health and Nutrition Examination Survey. Arch Intern Med 2011;171:1183-91. doi:10.1001/archinternmed.2011.257

25 Mente A, O’Donnell MJ, Rangarajan S, et al, PURE Investigators. Association of urinary sodium and potassium excretion with blood pressure. N Engl J Med 2014;371:601-11. doi:10.1056/ NEJMoa1311989

26 Mente A, Irvine EJ, Honey RJ, Logan AG. Urinary potassium is a clinically useful test to detect a poor quality diet. J Nutr 2009;139:743-9. doi:10.3945/jn.108.098319

27 Teo K, Chow CK, Vaz M, Rangarajan S, Yusuf SPURE InvestigatorsWriting Group. The Prospective Urban Rural Epidemiology (PURE) study: examining the impact of societal influences on chronic noncommunicable diseases in low-, middle-, and highincome countries. Am Heart / 2009;158:1-7.e1. doi:10.1016/j. ahj.2009.04.019

28 Yusuf S, Islam S, Chow CK, et al, Prospective Urban Rural Epidemiology (PURE) Study Investigators. Use of secondary prevention drugs for cardiovascular disease in the community in highincome, middle-income, and low-income countries (the PURE Study): a prospective epidemiological survey. Lancet 2011;378:1231-43. doi:10.1016/S0140-6736(11)61215-4

29 Teo K, Lear S, Islam S, et al, PURE Investigators. Prevalence of a healthy lifestyle among individuals with cardiovascular disease in high-, middle- and low-income countries: The Prospective Urban Rural Epidemiology (PURE) study. JAMA 2013;309:1613-21. doi:10.1001/jama.2013.3519

30 Kawasaki T, Itoh K, Uezono K, Sasaki H. A simple method for estimating $24 \mathrm{~h}$ urinary sodium and potassium excretion from second morning voiding urine specimen in adults. Clin Exp Pharmacol Physiol 1993;20:7-14. doi:10.1111/j.1440-1681.1993.tb01496.x

31 Mente A, O'Donnell MJ, Dagenais G, et al. Validation and comparison of three formulae to estimate sodium and potassium excretion from a single morning fasting urine compared to 24-h measures in 11 countries. J Hypertens 2014;32:1005-14, discussion 1015. doi:10.1097/HJH.0000000000000122

32 Yusuf S, Rangarajan S, Teo K, et al, PURE Investigators. Cardiovascular risk and events in 17 low-, middle-, and high-income countries. N Engl / Med 2014;371:818-27. doi:10.1056/NEJMoa1311890

33 Smyth A, Dehghan M, O'Donnell M, et al, ONTARGET and TRANSCEND Investigators. Healthy eating and reduced risk of cognitive decline: A cohort from 40 countries. Neurology 2015;84:2258-65. doi:10.1212/WNL.0000000000001638

34 Harrell F. Regression Modelling Strategies With Applications to Linear Models, Logistic Regression, and Survival Analysis. Springer-Verlag, 2001.

35 Holbrook JT, Patterson KY, Bodner JE, et al. Sodium and potassium intake and balance in adults consuming self-selected diets. Am J Clin Nutr 1984:40:786-93. doi:10.1093/ajcn/40.4.786

36 Krishna GG, Kapoor SC. Potassium supplementation ameliorates mineralocorticoid-induced sodium retention. Kidney Int 1993:43:1097-103. doi:10.1038/ki.1993.154

37 Penton D, Czogalla J, Loffing J. Dietary potassium and the renal control of salt balance and blood pressure. Pflugers Arch 2015;467:513-30. doi:10.1007/s00424-014-1673-1

38 Krishna GG, Kapoor SC. Potassium depletion exacerbates essential hypertension. Ann Intern Med 1991;115:77-83. doi:10.7326/00034819-115-2-77

39 Morris RC)r, Sebastian A, Forman A, Tanaka M, Schmidlin O. Normotensive salt sensitivity: effects of race and dietary potassium. Hypertension 1999;33:18-23. doi:10.1161/01.HYP.33.1.18

40 Sacks FM, Svetkey LP Vollmer WM et al, DASH-Sodium Collaborative Research Group. Effects on blood pressure of reduced dietary sodium and the Dietary Approaches to Stop Hypertension (DASH) diet. N Engl J Med 2001;344:3-10. doi:10.1056/NEJM200101043440101

41 Chang HY, Hu YW, Yue CS, et al. Effect of potassium-enriched salt on cardiovascular mortality and medical expenses of elderly men. Am J Clin Nutr 2006;83:1289-96. doi:10.1093/ajcn/83.6.1289

42 Li N, Yan LL, Niu W, et al. A large-scale cluster randomized trial to determine the effects of community-based dietary sodium reduction-the China Rural Health Initiative Sodium Reduction Study. Am Heart / 2013:166:815-22. doi:10.1016/j.ahj.2013.07.009

43 Estruch R, Ros E, Salas-Salvadó J, et al, PREDIMED Study Investigators. Primary Prevention of Cardiovascular Disease with a Mediterranean Diet Supplemented with Extra-Virgin Olive Oil or Nuts. N Engl) Med 2018;378:e34. doi:10.1056/NEIMoa1800389

44 Vasara E, Marakis G, Breda J, et al. Sodium and Potassium Intake in Healthy Adults in Thessaloniki Greater Metropolitan Area-The Salt Intake in Northern Greece (SING) Study. Nutrients 2017;9:E417. doi:10.3390/nu9040417

45 Serra-Majem L, Bes-Rastrollo M, Román-Viñas B, Pfrimer K, SánchezVillegas A, Martínez-González MA. Dietary patterns and nutritiona adequacy in a Mediterranean country. Br J Nutr 2009;101(Suppl 2):S21-8. doi:10.1017/S0007114509990559 
46 Mercado Cl, Cogswell ME, Perrine CG, Gillespie C. Diet Quality Associated with Total Sodium Intake among US Adults Aged $\geq 18$ Years-National Health and Nutrition Examination Survey, 20092012. Nutrients 2017;9:E1164. doi:10.3390/nu9111164

47 Cogswell ME, Wang CY, Chen TC, et al. Validity of predictive equations for 24-h urinary sodium excretion in adults aged 18-39 y. Am J Clin Nutr 2013;98:1502-13. doi:10.3945/ajcn.113.059436

48 Han W, Sun N, Chen Y, Wang H, Xi Y, Ma Z. Validation of the Spot Urine in Evaluating 24-Hour Sodium Excretion in Chinese Hypertension Patients. Am J Hypertens 2015;28:1368-75. doi:10.1093/ajh/ hpv037

49 Cogswell ME, Loria CM, Terry AL, et al. Estimated 24-Hour Urinary Sodium and Potassium Excretion in US Adults. JAMA 2018;319:1209-20. doi:10.1001/jama.2018.1156
50 World Health Organization. Strategies to monitor and evaluate population sodium consumption and sources of sodium in the diet- report of a joint technical meeting convened by WHO and the Government of Canada. Canada, October 2010. World Health Organization, 2011.

51 McCarron DA, Kazaks AG, Geerling JC, Stern JS, Graudal NA. Normal range of human dietary sodium intake: a perspective based on 24-hour urinary sodium excretion worldwide. Am J Hypertens 2013;26:1218-23.

52 Trieu K, Neal B, Hawkes C, et al. Salt Reduction Initiatives around the World - A Systematic Review of Progress towards the Global Target. PLoS One 2015;10:e0130247. doi:10.1371/journal.pone.0130247

Supplementary information: additional material 